\title{
Optimization of the Synthesis of Nanostructured Tungsten-Molybdenum Bimetallic Oxide
}

\author{
H. Hassan, ${ }^{1}$ T. Zaki, ${ }^{1}$ S. Mikhail, ${ }^{1}$ A. Kandil, ${ }^{2}$ and A. Farag ${ }^{2}$ \\ ${ }^{1}$ Petroleum Refining Division, Department of Catalysis, Egyptian Petroleum Research Institute, Cairo 11727, Egypt \\ ${ }^{2}$ Department of Chemistry, Faculty of Science, Helwan University, Helwan 11421, Egypt
}

Correspondence should be addressed to H. Hassan, hebachem@yahoo.com

Received 16 May 2012; Accepted 10 June 2012

Academic Editors: R. Azimirad, C. Li, and F. Miao

Copyright $(2012$ H. Hassan et al. This is an open access article distributed under the Creative Commons Attribution License, which permits unrestricted use, distribution, and reproduction in any medium, provided the original work is properly cited.

\begin{abstract}
$\mathrm{Mo}_{0.5} \mathrm{~W}_{0.5} \mathrm{O}_{3}$ nanoparticles were prepared through the Pechini process and were characterized using X-ray diffraction (XRD), transmission electron microscopy (TEM), FT-IR spectrometer, and differential thermal analysis (TG-DSC) analyses. The polyesterification reaction, as the starting step, has a profound influence on the dispersion of the resulting nanoparticles. The molar ratios $\mathrm{CA}: \mathrm{TM}=2$ and $\mathrm{EG}: \mathrm{CA}=1.5$ are favorable for the preparation of $\mathrm{Mo}_{0.5} \mathrm{~W}_{0.5} \mathrm{O}_{3}$ nanoparticles having average particles size ranging from 2 to $9 \mathrm{~nm}$. Meanwhile, the molar ratios $\mathrm{CA}: \mathrm{TM}=4$ and $\mathrm{EG}: \mathrm{CA}=0.19$ are favorable for the preparation of $\mathrm{Mo}_{0.5} \mathrm{~W}_{0.5} \mathrm{O}_{3}$ nanoparticles having an average particles size ranging from 11 to $29 \mathrm{~nm}$. For the calcination step, increased calcination time (eight hours) at $500^{\circ} \mathrm{C}$ is advantageous for allowing the monometallic phases enough time to transform into the desired bimetallic $\mathrm{Mo}_{0.5} \mathrm{~W}_{0.5} \mathrm{O}_{3}$ phase.
\end{abstract}

\section{Introduction}

Molybdenum trioxide $\left(\mathrm{MoO}_{3}\right)$ and tungsten trioxide $\left(\mathrm{WO}_{3}\right)$ are well-known metal oxides with similar physical and chemical properties. They show n-type semiconducting properties related to the presence of lattice defects, mainly oxygen defects $[1,2]$, and they have been extensively studied for their potential applicability in gas sensing devices $[3,4]$ and catalysis [5,6]. Additionally, due to the unique activity of trioxides of W and Mo in nonstoichiometric forms, they have been extensively studied as electrochemical materials [7].

The $\mathrm{Mo}_{x} \mathrm{~W}_{l-x} \mathrm{O}_{3}$ system exhibits "displacive" or "reconstructive" phase transitions induced by hydrogen intercalation and temperature, respectively, leading to rearrangement in the local electronic and atomic structures [8]. Polycrystalline $\mathrm{Mo}_{x} \mathrm{~W}_{l-x} \mathrm{O}_{3}(x=0.1,0.2,0.3,0.5,0.7$, and 0.9$)$ solid solutions were obtained by high-temperature synthesis [9].

With the progress in nanotechnology, nanoparticles have attracted increasing attention to their unique properties [10]. One of the recently investigated methods for the simple preparation of nano-oxide composites that include molybdenum or tungsten atoms is the Pechini method $[11,12]$. However, research into the catalytic activity of molybdenum-tungsten bimetallic oxides is rare despite their promising gas sensing potential $[13,14]$.

In this work, the synthesis of molybdenum-tungsten oxide nanoparticles is presented. The procedure includes the formation of composites containing both molybdenum or tungsten atoms in a $1: 1$ ratio using the polymeric method. The influence of citric acid and ethylene glycol concentrations, as well as total metal molar ratios, on the properties of the final products was studied. In addition, the effect of the sequence of the synthetic steps (i.e., polymerization and chelation) was explored. Furthermore, the impacts of the temperature and time of calcination were examined.

\section{Experimental}

For most of the prepared samples, aqueous ethylene glycol (EG) solutions of different concentrations were added to an aqueous solution of citric acid (CA) for polymerization under constant stirring and at $60^{\circ} \mathrm{C}$ for $1 \mathrm{~h}$. Second, the polyester was heated to $80^{\circ} \mathrm{C}$ with stirring, and then $500 \mathrm{~mL}$ of a TM solution (1:1 Mo:W metal ratio of ammonium 
heptamolybdate and ammonium metatungstate precursors) was added and stirred for an additional hour. Accordingly, molybdic and tungstic acids were created, and the $\mathrm{pH}$ of the medium decreased to 1.4. In the third step, the solutions were slowly heated to $140^{\circ} \mathrm{C}$ until the water was completely removed ( $\sim 2.5$ hours). The gels obtained were dried at $150^{\circ} \mathrm{C}$ overnight in an electrical furnace to yield solid resins. The resulting resins were ground in an agate mortar and subjected to a pyrolysis process at $450^{\circ} \mathrm{C}$ for $4 \mathrm{~h}$ in glazed alumina crucibles. Finally, the pyrolyzed product was subjected to calcination at $500^{\circ} \mathrm{C}$ for $4 \mathrm{~h}$ in the presence of purified air. The $\mathrm{MoWO}_{3}$ samples were named $M W R_{C^{-}}$ $R_{E}\left(R_{C}\right.$ is $\mathrm{CA}: \mathrm{TM}$, and $R_{E}$ is $\left.\mathrm{EG}: \mathrm{CA}\right)$ corresponding to the ratios used.

To understand the influence of the sequence of the preparation steps, MW2-1.5 was also prepared in the reverse fashion (i.e., the TM solution was added to the CA solution at $60^{\circ} \mathrm{C}$ first, and then, the EG solution was added at $80^{\circ} \mathrm{C}$ ). This sample was named RMW2-1.5.

To study the role of the calcination step on the final characteristics of the produced bimetallic oxides, two factors were investigated. The first factor was the calcination temperature, and the second was the calcination duration.

The molybdenum-tungsten samples selected for thermal treatment temperature evaluation were named $M W R_{C^{-}}$ $R_{E}(T)\left(R_{C}\right.$ is CA:TM, $R_{E}$ is EG: CA and $T$ is calcination temperature) corresponding to the preparation and treatment conditions used. At relatively high calcination temperatures, that is, 750,850 , and $950^{\circ} \mathrm{C}$, a physically separated needled sample was collected in addition to the ordinary final powder product, and the separated samples were coded $\mathrm{MWR}_{C}-R_{E}(\mathrm{~S} 750), \mathrm{MWR} R_{C}-R_{E}(\mathrm{~S} 850)$, and $\mathrm{MWR} R_{C}-R_{E}(\mathrm{~S} 950)$, respectively.

The bimetallic oxide samples subjected to different calcination times were labeled $M W R_{C}-R_{E}(8)$ and $M W R_{C^{-}}$ $R_{E}$ (12), which referred to calcination for eight and twelve hours, respectively. The sample calcined for four hours was named $M W R_{C}-R_{E}$.

The evolution of the samples was followed by X-ray powder diffraction (XRD) on a Bruker AXS D8 Advance equipped with $\mathrm{Ni}$-filtered copper $\mathrm{K} \alpha 1$ radiation $(\lambda=$ $1.5404 \AA$ ) in the range $2 \theta=20-80^{\circ}$. Transmission electron microscopy images were recorded on a JEOL-1400 TEM at $120 \mathrm{kV}$. FTIR spectra were recorded using an FT-IR spectrometer, model 960M000 g, ATI Mattson Infinity Series. Differential thermal analysis was recorded on a Labsys TGDSC16 apparatus manufactured by Setaram Instrumentation. The sample was ground to 20 mesh, and $\alpha$-alumina was used as an inert reference material. The experiments were carried out at a heating rate of $10^{\circ} \mathrm{C} / \mathrm{min}$ in an argon atmosphere.

\section{Results and Discussion}

\subsection{The Role of Reactant Molar Ratios}

3.1.1. Influence of EG Molar Ratio. Figure 1 presents the XRD patterns of MoW oxides samples with increasing EG molar fractions and a constant CA:TM molar ratio. The XRD patterns show one main phase, which is $\mathrm{Mo}_{0.5} \mathrm{~W}_{0.5} \mathrm{O}_{3}$ (JCPD: 28-0667), and two secondary phases, monoclinic $\mathrm{MoO}_{3}$ (JCPD: 80-0347) and cubic $\mathrm{WO}_{3}$ (JCPD: 41-0905), in all the samples tested. TEM images (Figures 2(a) and 2(b)) reveal that the average particle size increased (from $3-10 \mathrm{~nm}$ to $10-16 \mathrm{~nm}$ ) as the EG molar fraction increased (from MW1-3 to MW1-6).

With increasing EG molar fractions, the average particle size continued to increase up to $18 \mathrm{~nm}$ (Figure 2(c), MW112 ), and aggregates started to appear. Both particle enlargement and aggregation became more obvious in the MW1-24 sample (Figure 2(d)), which was prepared using the highest molar fraction of EG.

3.1.2. Influence of CA Molar Ratio. According to previous experimental data, the MW1-3 sample has bimetallic nanoparticles that were prepared using the optimum EG molar ratio, so this sample was selected. Thus, the EG molar ratios versus TM and CA of 1 and 3, respectively, were selected as the initial values for studying the influence of the CA molar ratio on the properties of the produced bimetallic nanoparticles.

Figure 3 presents the XRD patterns of MoW oxide samples prepared using different CA molar ratios versus both TM and EG. According to Figure $3(\mathrm{~b}), \mathrm{Mo}_{0.5} \mathrm{~W}_{0.5} \mathrm{O}_{3}$ was the only phase in MW2-1.5. However, the other samples (MW13, MW4-0.75, MW8-0.38, and MW16-0.19) contained secondary phases of $\mathrm{MoO}_{3}$ and $\mathrm{WO}_{3}$ in addition to the major phase $\left(\mathrm{Mo}_{0.5} \mathrm{~W}_{0.5} \mathrm{O}_{3}\right)$. The XRD patterns did not reveal any change in the intensities of the $\mathrm{Mo}_{0.5} \mathrm{~W}_{0.5} \mathrm{O}_{3}$ reflections with an increasing CA molar ratio.

TEM images (Figures 4(a) and 4(b)) indicated that the average particle size increased from $3-10 \mathrm{~nm}$ to $4-16 \mathrm{~nm}$ as the CA molar ratio increased (from MW1-3 to MW21.5). However, when the CA molar ratio increased four and eight times, as in the case of MW8-0.38 and MW160.19 , respectively, the average particle size increased from 4-16 nm (Figure 4(b)) to 11-19 nm (Figure 4(c)) and 20$36 \mathrm{~nm}$ (Figure 4(d)).

Despite the slightly increased size of the MW2-1.5 nanoparticles in comparison to the MW1-3 nanoparticles (Figures 4(a) and 4(b)), the presence of the $\mathrm{Mo}_{0.5} \mathrm{~W}_{0.5} \mathrm{O}_{3}$ phase as a mono-phase gave this sample unique properties.

\subsubsection{Influence of the Sequence of Preparation Steps. Figure 5} presents XRD patterns of both MW2-1.5 and RMW2-1.5 samples. This figure shows that starting with the chelation reaction (i.e., the reaction between TM and CA) did not alter the nature of the final phase when $\mathrm{Mo}_{0.5} \mathrm{~W}_{0.5} \mathrm{O}_{3}$ was the only phase (e.g., MW2-1.5). However, the crystallinity of the produced phase decreased with a change to the sequence of preparation steps.

The TEM images of both samples (Figure 6) did not reveal the average particle size shift due to the rearranged order of the preparation steps. However, in RMW2-1.5, the prepared $\mathrm{Mo}_{0.5} \mathrm{~W}_{0.5} \mathrm{O}_{3}$ appeared as aggregations, while the 


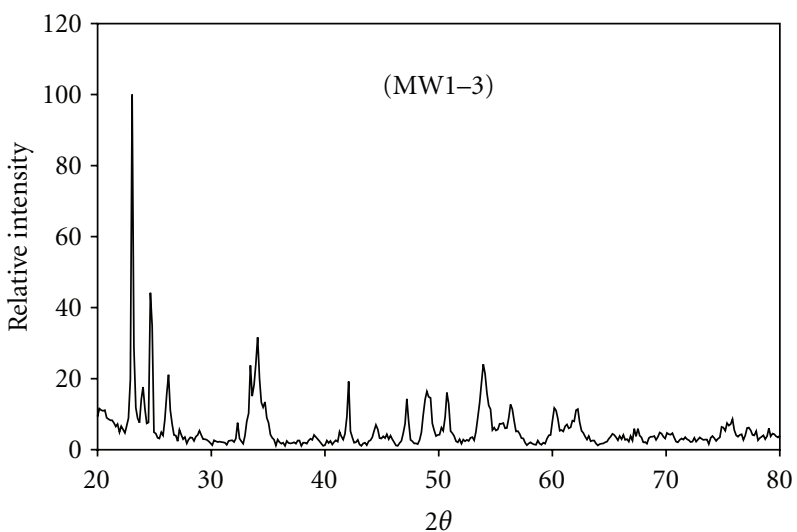

(a)

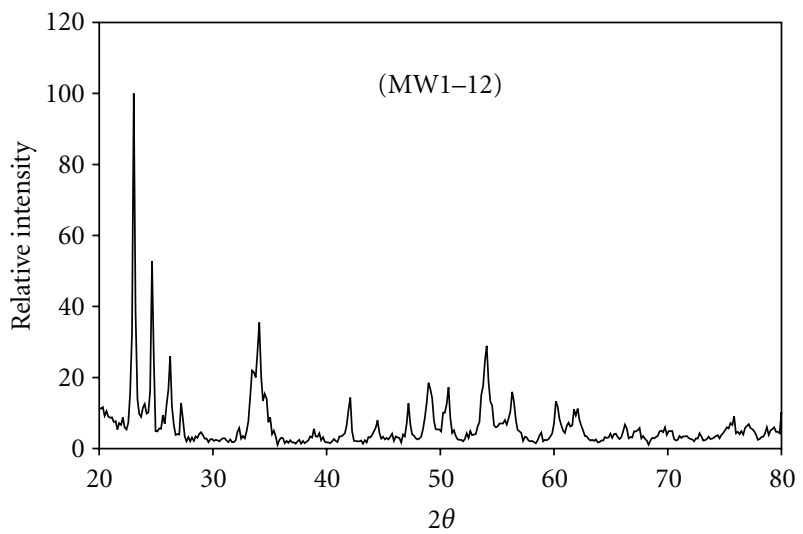

(c)

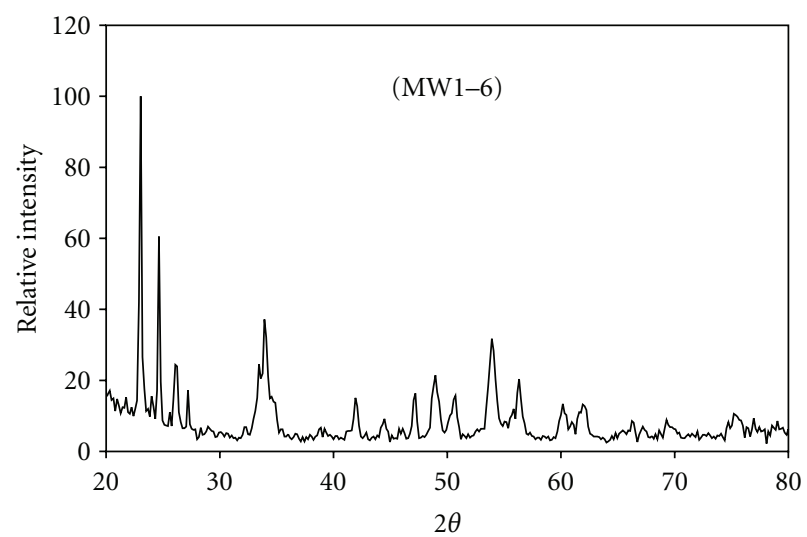

(b)

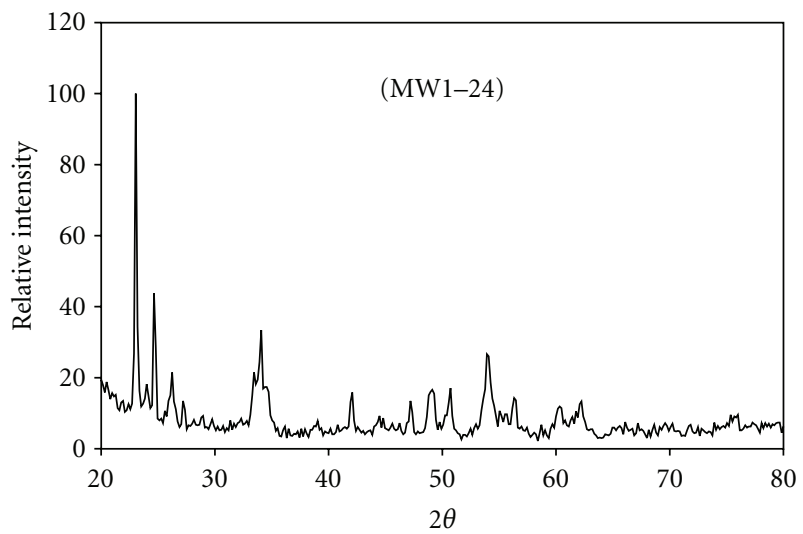

(d)

Figure 1: XRD patterns of (a) MW1-3 (b) MW1-6, (c) MW1-12 and (d) MW1-24.

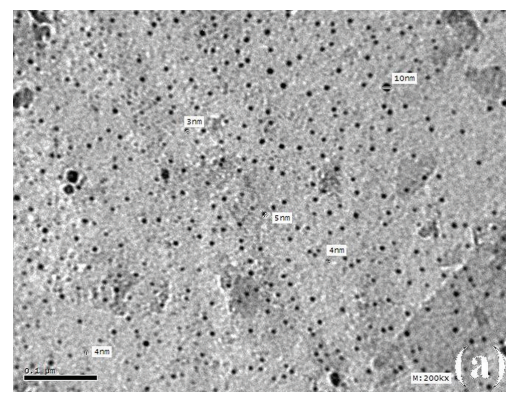

(a)

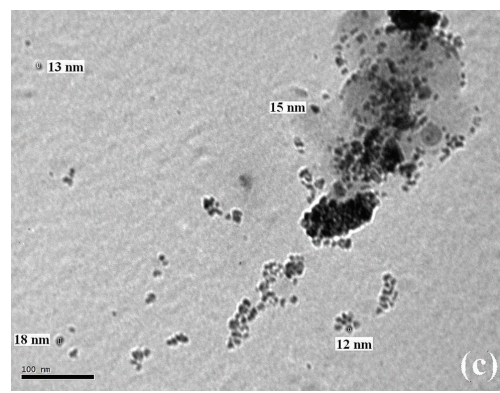

(c)

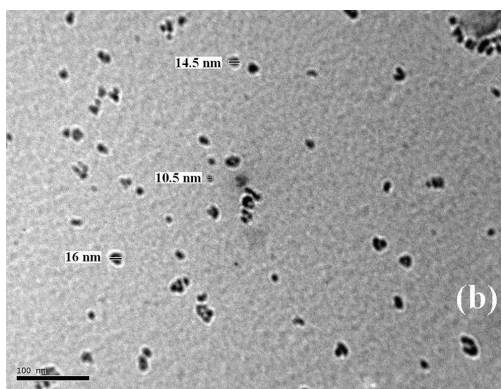

(b)

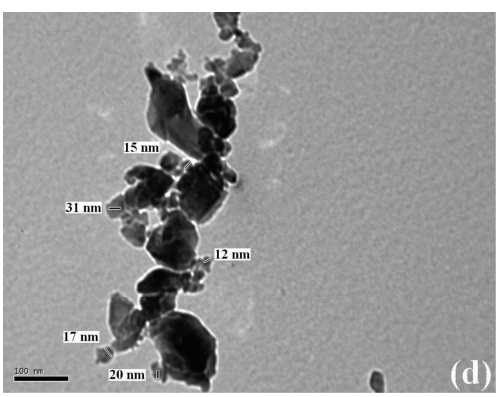

(d)

FIGURE 2: Transmission electron micrographs of nanocrystalline particles of (a) MW1-3, (b) MW1-6, (c) MW1-12, and (d) MW1-24. 


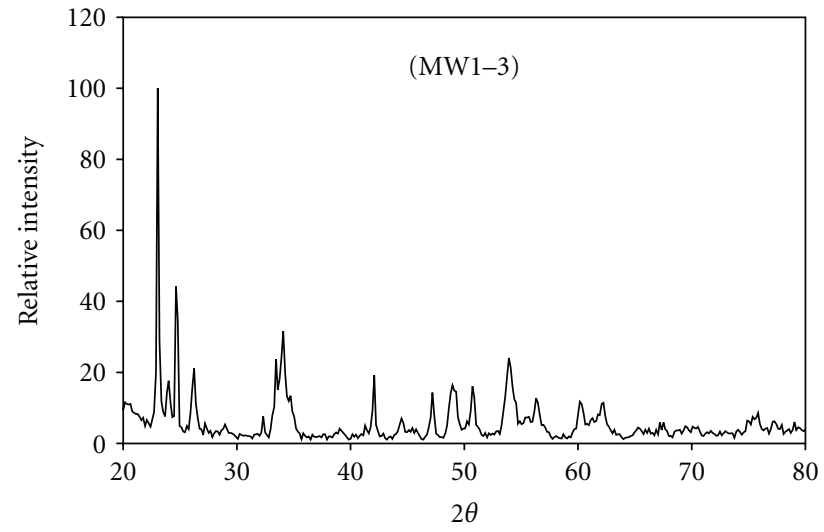

(a)

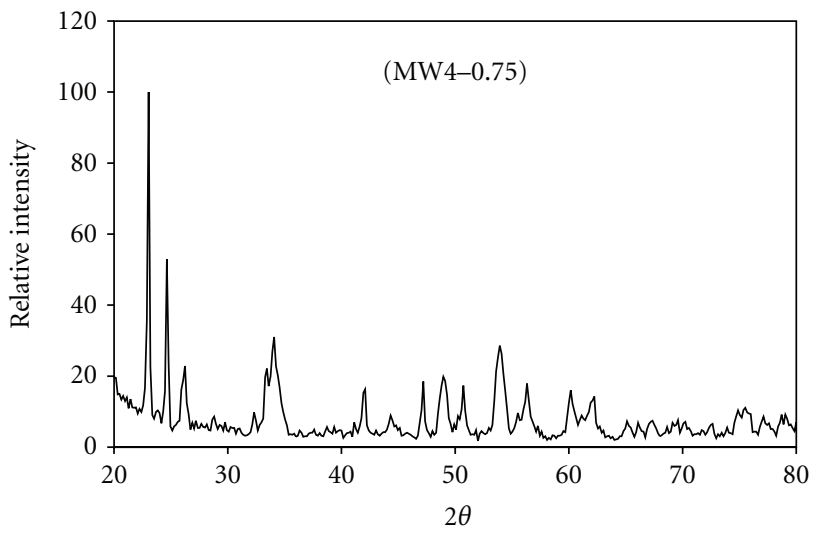

(c)

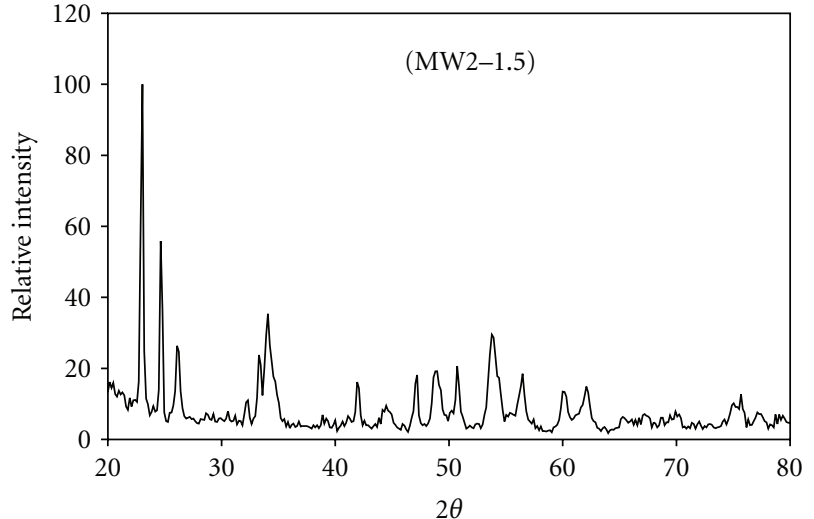

(b)

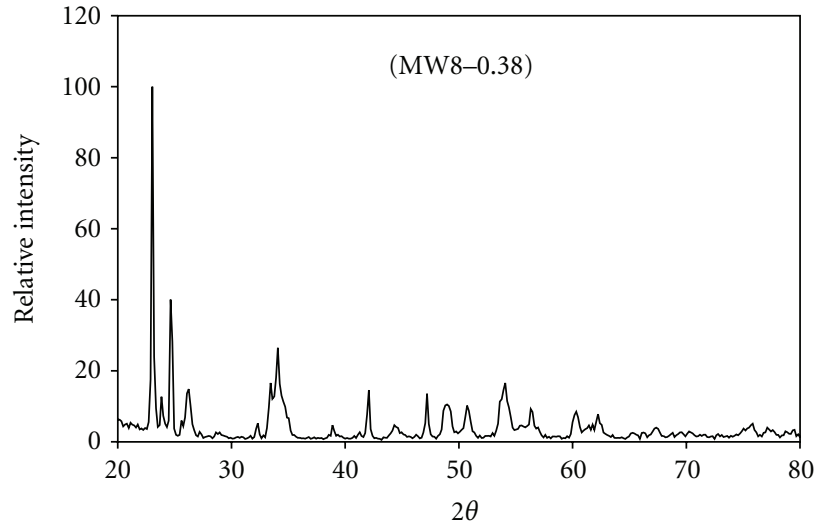

(d)

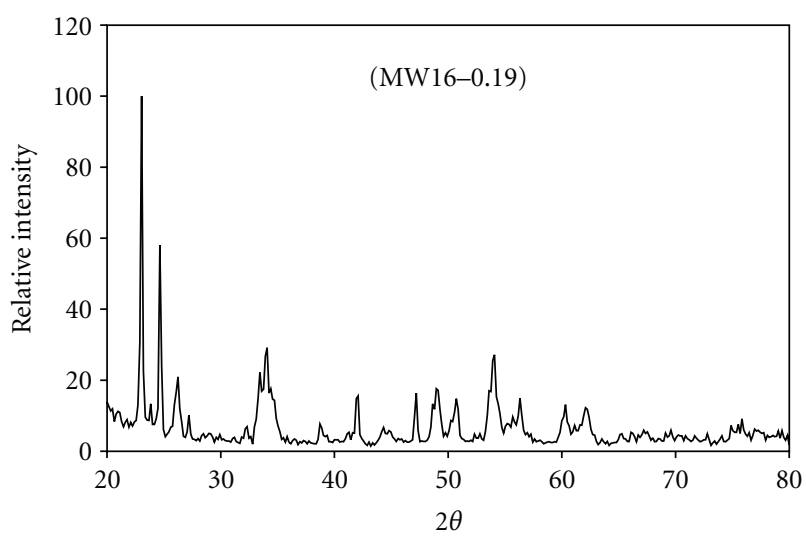

(e)

Figure 3: XRD patterns of (a) MW1-3, (b) MW2-1.5, (c) MW4-0.75, (d) MW8-0.38, and (e) MW16-0.19.

MW2-1.5 sample showed the $\mathrm{Mo}_{0.5} \mathrm{~W}_{0.5} \mathrm{O}_{3}$ as well dispersed nanoparticles.

3.1.4. Influence of TM Molar Ratio. To investigate the influence of the TM molar ratio on the properties of the produced nanoparticles, a reactant mixture with excess citric acid was chosen because the CA plays the main role in the chelation step. Accordingly, CA molar ratios versus TM and EG of 16 and 0.19, respectively (MW16-0.19), were selected for studying the influence of the TM molar fraction on the properties of the produced bimetallic nanoparticles.

Figure 7 presents the XRD patterns of MoW oxide samples prepared using regular increments of TM molar ratios against CA and EG. In Figure 7(b), the XRD pattern of MW8-0.19 indicated duplication of the intensities of the reflections related to the $\mathrm{Mo}_{0.5} \mathrm{~W}_{0.5} \mathrm{O}_{3}$ phase. The same reflections were seen in the pattern of MW16-0.19 (Figure $7(\mathrm{a})$ ), but the $\mathrm{WO}_{3}$ and $\mathrm{MoO}_{3}$ phases were still present in the prepared sample. 


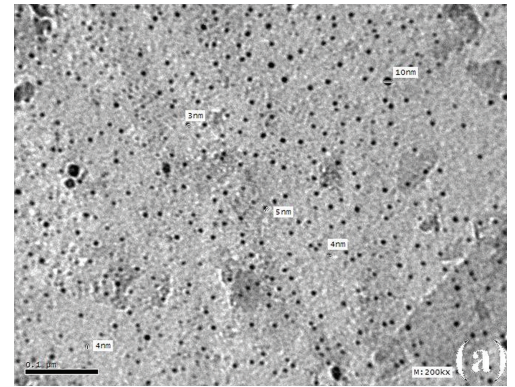

(a)

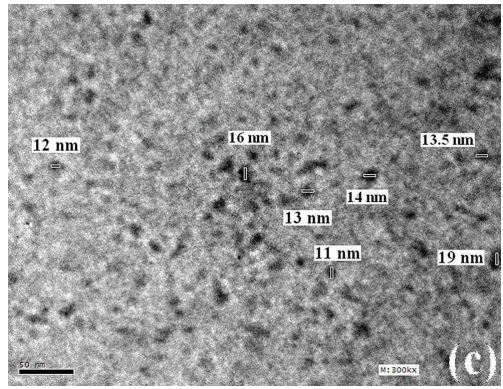

(c)

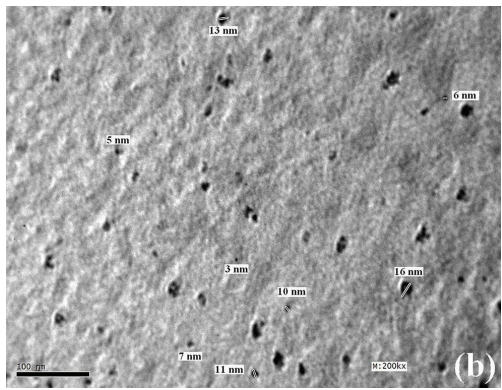

(b)

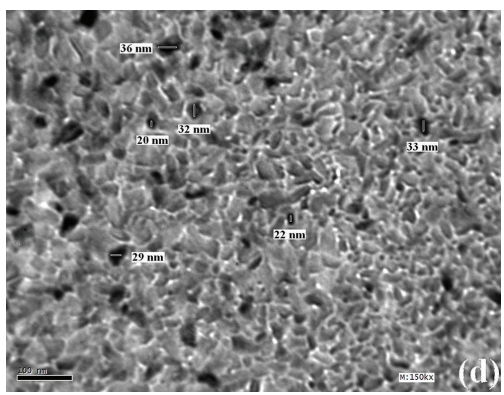

(d)

Figure 4: Transmission electron micrographs of nanocrystalline particles of (a) MW1-3, (b) MW2-1.5, (c) MW8-0.38, and (d) MW160.19 .

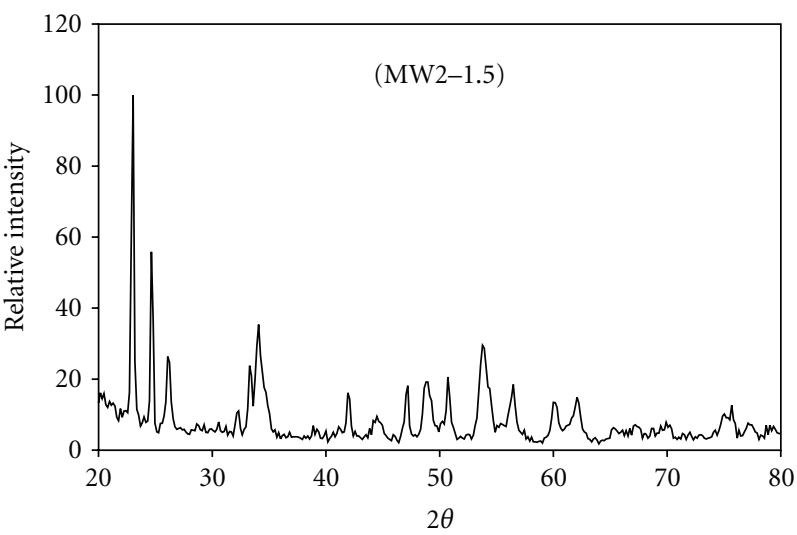

(a)

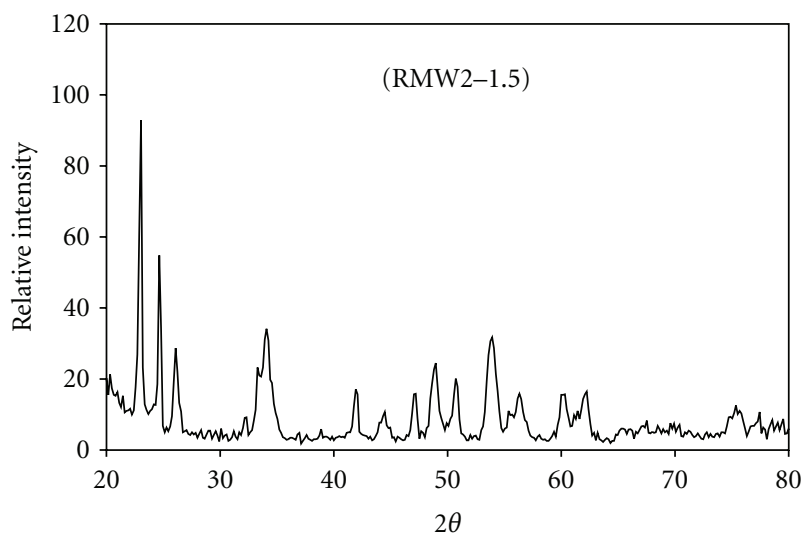

(b)

FIgURE 5: XRD patterns of (a) MW2-1.5 and (b) RMW2-1.5.

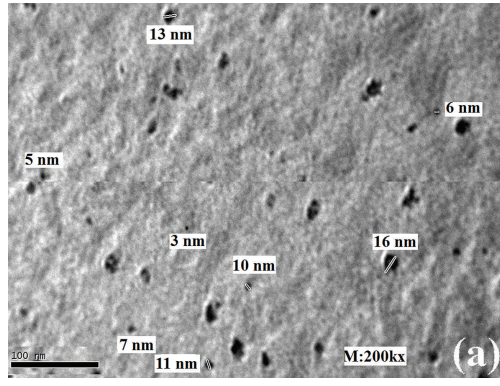

(a)

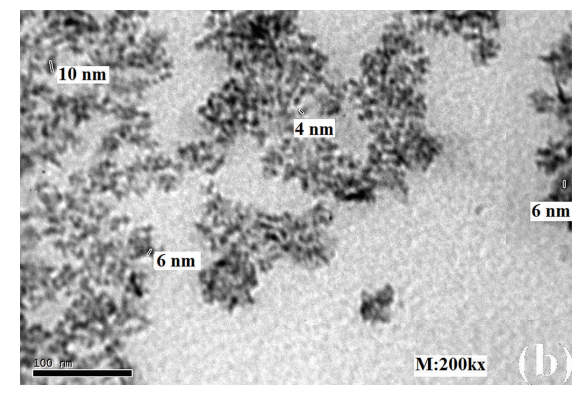

(b)

FIgURE 6: Transmission electron micrographs of nanocrystalline particles of (a) MW2-1.5 and (b) RMW2-1.5. 


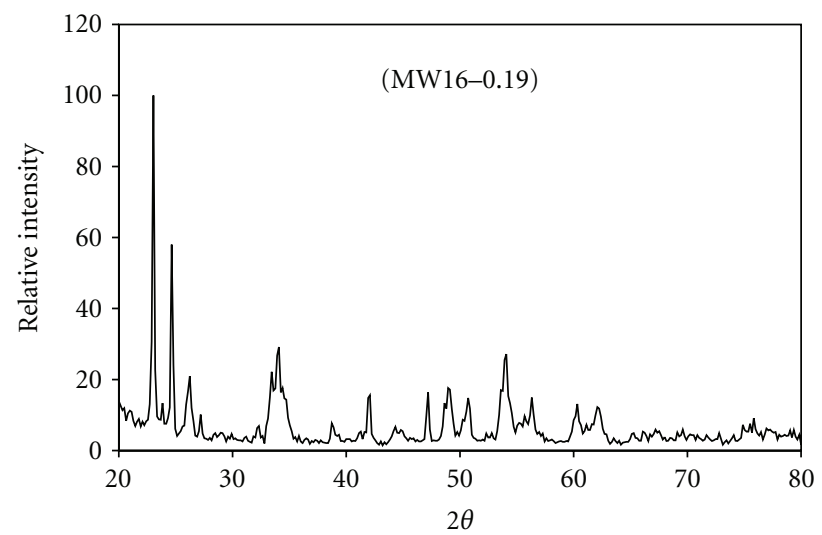

(a)

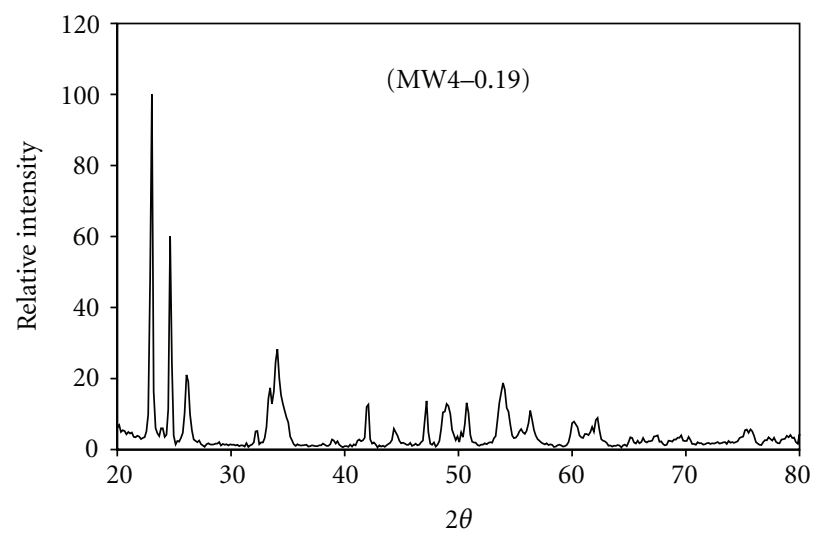

(c)

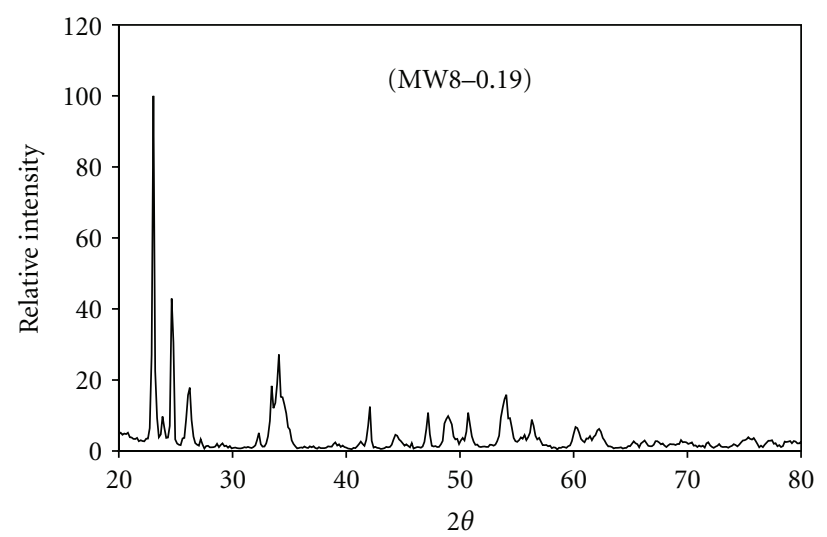

(b)

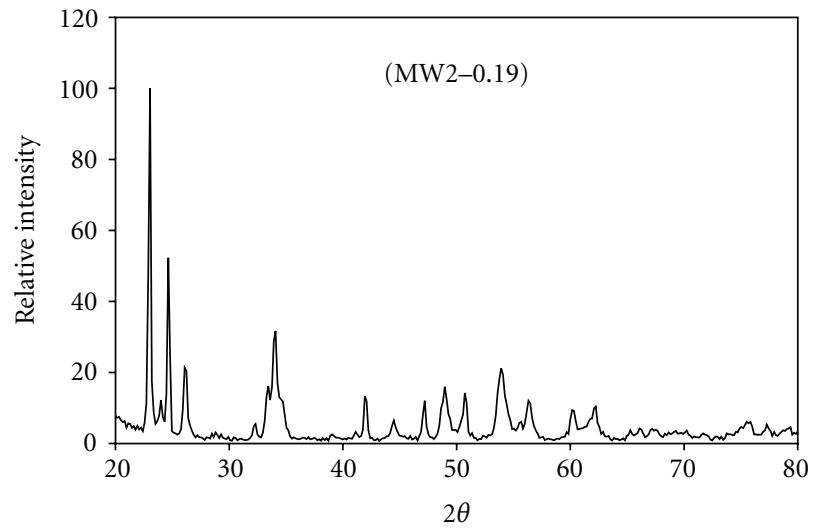

(d)

Figure 7: XRD patterns of (a) MW16-0.19, (b) MW8-0.19, (c) MW4-0.19, and (d) MW2-0.19.

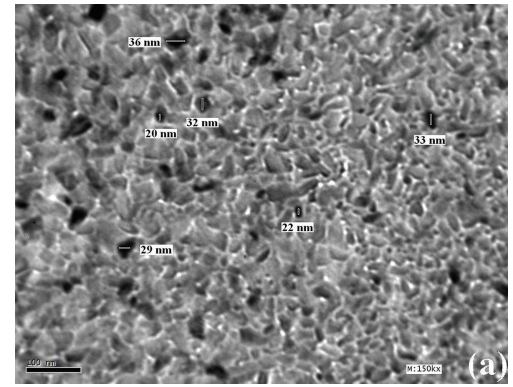

(a)

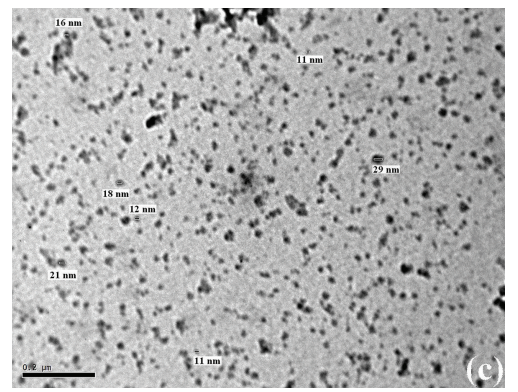

(c)

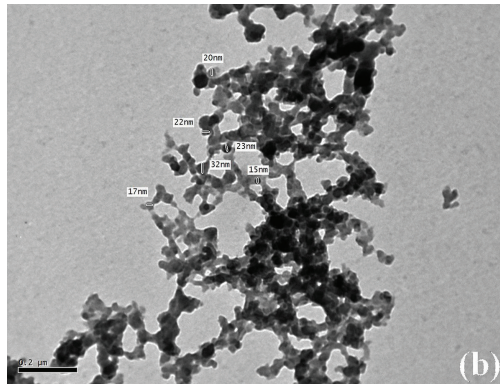

(b)

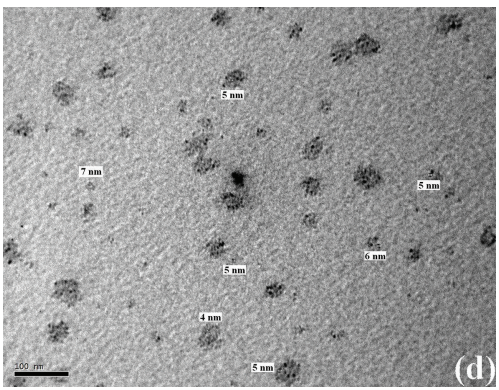

(d)

FIGURE 8: Transmission electron micrographs of nanocrystalline particles of (a) MW16-0.19, (b) MW8-0.19, (c) MW4-0.19, and (d) MW20.19 . 
On the other hand, the $\mathrm{Mo}_{0.5} \mathrm{~W}_{0.5} \mathrm{O}_{3}$ phase became the unique phase with further increases in the molar ratio of TM, whereas the XRD pattern of MW4-0.19 (Figure 7(c)) indicated the absence of $\mathrm{WO}_{3}$ and $\mathrm{MoO}_{3}$ reflections. Furthermore, the reflections related to the $\mathrm{Mo}_{0.5} \mathrm{~W}_{0.5} \mathrm{O}_{3}$ phase increased in comparison with the XRD pattern of MW8-0.19 (Figure 7(b)).

Further increasing the TM molar ratio versus CA and EG (i.e., the CA molar ratios versus TM and EG became 2 and 0.19 , resp., (MW2-0.19)), the secondary phases $\mathrm{WO}_{3}$ and $\mathrm{MoO}_{3}$ returned to the final product along with $\mathrm{Mo}_{0.5} \mathrm{~W}_{0.5} \mathrm{O}_{3}$ (Figure $7(\mathrm{~d})$ ). Consequently, the reflection intensity of the main phase decreased in comparison with the MW4-0.19 sample (Figure 7(c)). TEM images (Figures 8(a) and 8(b)) of the same samples demonstrated that the average particle size decreased from $20-36 \mathrm{~nm}$ to $15-32 \mathrm{~nm}$ as the TM molar ratio increased. Upon further increases in the TM molar ratio (MW4-0.19), the average particle size gradually decreased to 11-29 nm (Figure 8(c)).

In the highest TM molar ratio sample (MW2-0.19), the average particle size was drastically smaller than that of the other samples. The TEM images of the samples illustrated nanoparticles with average sizes in the range of 4-7 nm (Figure 8(d)). In addition, nonmeasurable ultra-fine nanoparticles with diameters smaller than $2 \mathrm{~nm}$ appeared as dark gray patches distributed around the larger nanoparticles, which appeared as black spots.

3.2. The Role of the Thermal Treatment. The products of the polymerization-chelation reactions were subjected to two different types of thermal treatment. The first thermal treatment was pyrolysis in a nitrogen atmosphere at $450^{\circ} \mathrm{C}$ for four hours. The second treatment was calcination, which varied by temperature and time. At relatively high calcination temperatures (i.e., 750,850 , and $950^{\circ} \mathrm{C}$ ), physically separated needle samples were collected in addition to the ordinary powdered final products, and the new separated samples were named MW1-3(S750), MW1-3(S850), and MW13(S950), respectively.

3.2.1. Influence of Calcination Temperature. The X-ray diffraction patterns of nanoparticles produced at different thermal treatment temperatures (Figure 9) showed that for the lowest calcination temperature $\left(450^{\circ} \mathrm{C}, \mathrm{MW} 1-3(450)\right.$, Figure $9(\mathrm{a})$ ) and the sample calcined at $600^{\circ} \mathrm{C}$ (Figure 9(c)), the intensity of the strongest reflection (monoclinic $\mathrm{MoO}_{3}$ (JCPD: 80-0347) and cubic $\mathrm{WO}_{3}$ (JCPD: 41-0905) at a distance of $3.71 \AA$ ) increased. Meanwhile, the intensity of the strongest reflection $\left(\mathrm{Mo}_{0.5} \mathrm{~W}_{0.5} \mathrm{O}_{3}\right.$, JCPD: $28-0667$ at a distance of $3.783 \AA$ ) decreased with respect to the XRD pattern of the MW1-3 sample, which was calcined at $500^{\circ} \mathrm{C}$ (Figure 9(b)). Nevertheless, the previously mentioned phases were the only phases created on the final product. As the calcination temperature increased to $750^{\circ} \mathrm{C}$ (Figure 9(d)), a thermal deformation of the bimetallic nanoparticles occurred where the expected phase $\mathrm{Mo}_{0.5} \mathrm{~W}_{0.5} \mathrm{O}_{3}$ disappeared and was replaced by two deformed phases: $\mathrm{W}_{0.47} \mathrm{Mo}_{0.53} \mathrm{O}_{3}$ (JCPD: 32-1392) and $\mathrm{W}_{0.4} \mathrm{Mo}_{0.6} \mathrm{O}_{3}$ (JCPD: 76-1280). The monometallic nanoparticles, which were monoclinic $\mathrm{MoO}_{3}$ (JCPD: 80-0347) and cubic $\mathrm{WO}_{3}$ (JCPD: 41-0905), remained in the final powdered sample. However, a new, physically needled phase was easily separated manually from the product after cooling. This needled sample, named MW1-3(S750), was subjected to X-ray diffraction analysis in the range $2 \theta=4-80^{\circ}$, which indicated that this phase consisted mainly of monoclinic $\mathrm{MoO}_{3}$ (JCPD: 47-1320), and orthorhombic $\mathrm{MoO}_{3}$ (JCPD: 05-0508) (Figure 10(a)).

Upon increasing the calcination temperature to $850^{\circ} \mathrm{C}$ (Figure 9(e)), the deformed bimetallic phases in MW1$3(750)$ were replaced with a new phase $\left(\mathrm{W}_{0.71} \mathrm{Mo}_{0.29} \mathrm{O}_{3}\right.$, JCPD: 76-1279) for the sample MW1-3(850), in which tungsten is the major component. In addition to the bimetallic oxide, the monometallic oxides monoclinic $\mathrm{MoO}_{3}$ (JCPD: 80-0347) and $\mathrm{WO}_{3}$ (JCPD: 01-0486) were still present in the final powdered product (Figure 9(e)).

The crystallinity of the molybdenum oxides present in the physically separated needled sample (MW1-3(S850), Figure 10(b)), monoclinic $\mathrm{MoO}_{3}$ (JCPD: 47-1320), and orthorhombic $\mathrm{MoO}_{3}$ (JCPD: 05-0508), increased sharply, as indicated from the strong enhancement in reflection intensities with respect to MW1-3(S750) (Figure 10(a)). The decrease in the intensity of the noisy hump that occurred in the range of $2 \theta=4-20^{\circ}$ also indicated the increased crystallinity.

Finally, at the highest calcination temperature $\left(950^{\circ} \mathrm{C}\right)$, complete separation between the two metals in the oxide occurred, whereas the XRD pattern of the powdered sample, MW1-3(950), indicated that the sample contained only a triclinic $\mathrm{WO}_{3}$ (JCPD: 32-1395) phase (Figure 9(e)). Meanwhile, the XRD pattern of the needled sample, MW13(S950), indicated that this sample consisted of monoclinic $\mathrm{MoO}_{3}$ (JCPD: 47-1320), and orthorhombic $\mathrm{MoO}_{3}$ (JCPD: 05-0508) phases accompanied with strongly increased crystallinity of the molybdenum oxides (Figure 10(c)).

The elucidation of powdered sample XRD patterns was facilitated by using the FT-IR spectra of MW1-3 and MW1-3(950) in Figure 11. The FT-IR spectrum of MW13 identified a broad band located in the range of 475$1050 \mathrm{~cm}^{-1}$, which had distinguishable apexes at 633, 767, 845 , and $975 \mathrm{~cm}^{-1}$ (Figure 11(a)). The band located at $975 \mathrm{~cm}^{-1}$ was assigned to $(\mathrm{W}=\mathrm{O})$ and $(\mathrm{Mo}=\mathrm{O})$ terminal groups $[15,16]$, while the bands at 633 and $845 \mathrm{~cm}^{-1}$ were attributed to the asymmetric and symmetric stretches of $\mathrm{W}-$ O-W bridges, respectively $[15,17,18]$.

According to the literature, vibration of the Mo-O-Mo bond should result in a band with an apex wavenumber of $882 \mathrm{~cm}^{-1}$ [16]. There was no clear band at this spot, but we could identify a broadband covering surrounding wavenumbers.

The band at $767 \mathrm{~cm}^{-1}$ was assigned to Mo-O-W stretching. This assumption was possible due to its absence in the spectrum of MW1-3(950), while the broadband that covered the range of $475-1050 \mathrm{~cm}^{-1}$ was split into two apexes at 633 and $845 \mathrm{~cm}^{-1}$ (Figure 11(b)). The FT-IR spectrum of MW1-3(950) nanoparticles illustrated a narrowing in this 


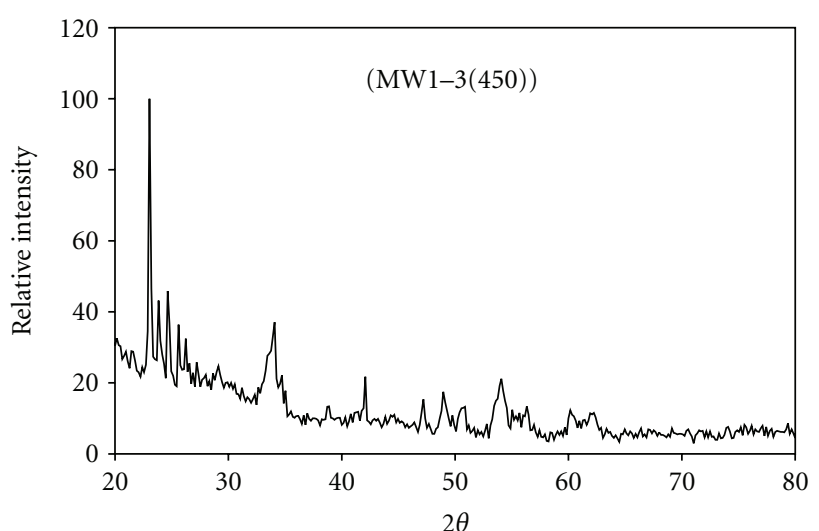

(a)

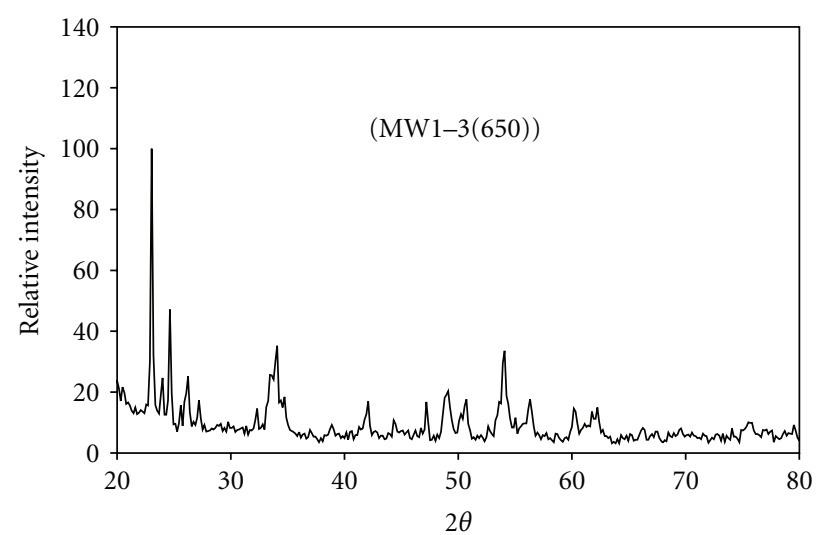

(c)

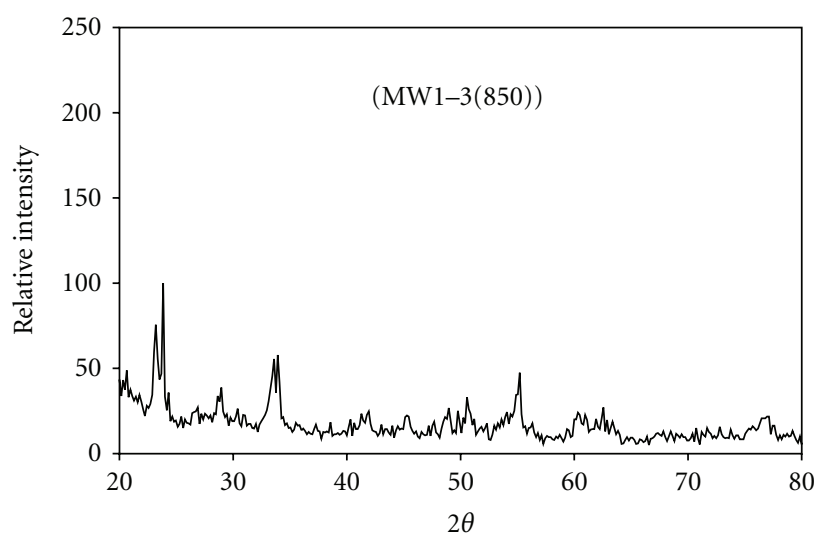

(e)

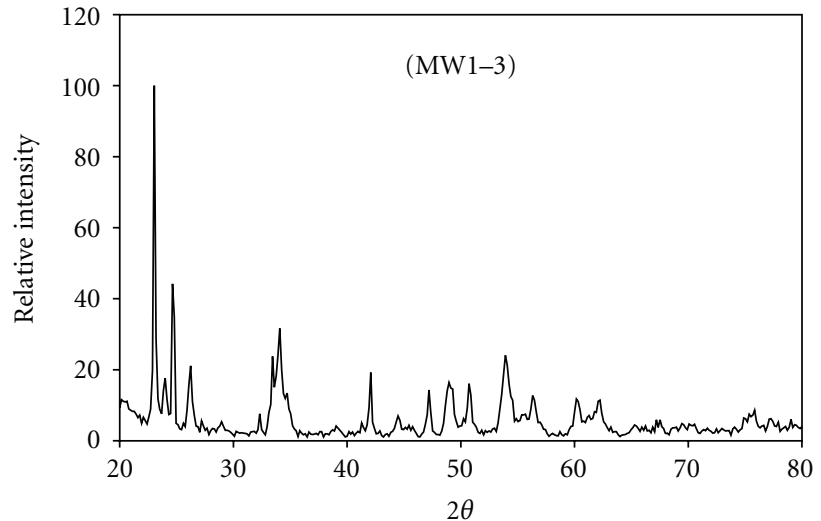

(b)

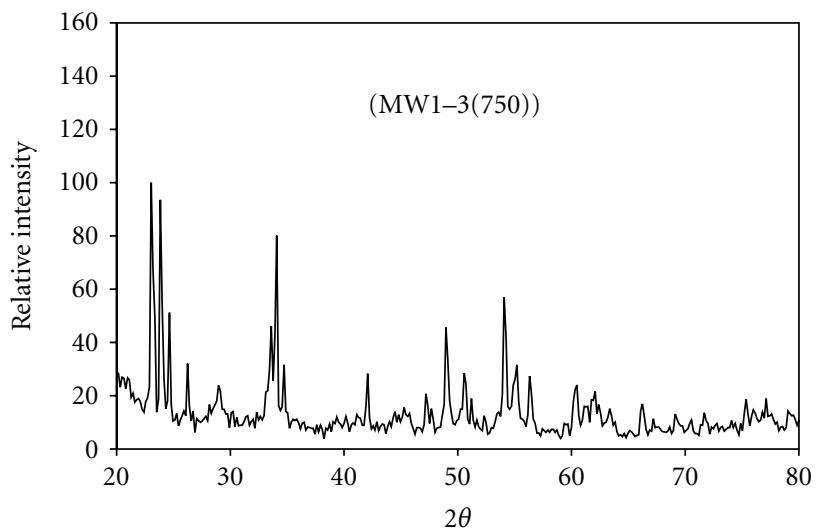

(d)

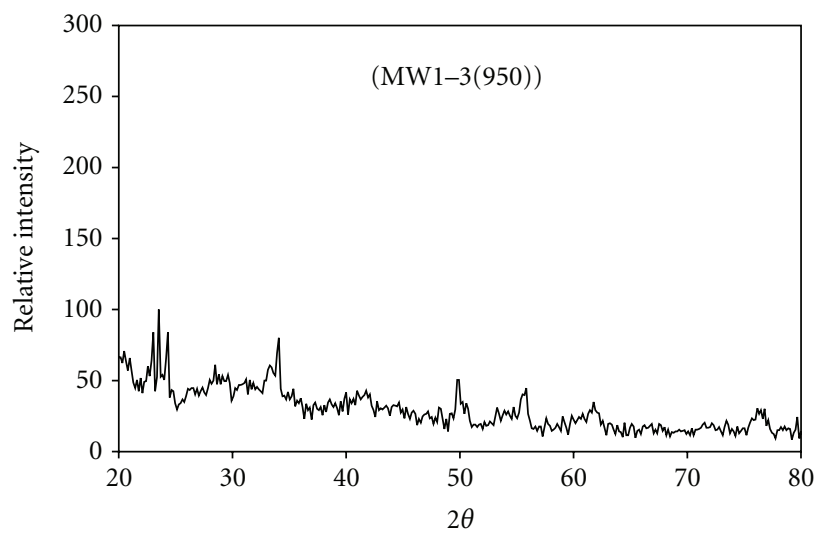

(f)

Figure 9: XRD patterns of (a) MW1-3(450), (b) MW1-3, (c) MW1-3(650), (d) MW1-3(750), (e) MW1-3(850), and (f) MW1-3(950).

peak due to the absence of bands related to the vibration of the Mo-O-Mo bond at $882 \mathrm{~cm}^{-1}$. Moreover, a new shoulder appeared at $1040 \mathrm{~cm}^{-1}$ and was attributed to the stretching of W-O bonds at the surface [18]. The band at $1620 \mathrm{~cm}^{-1}$ was assigned to the $\mathrm{H}-\mathrm{O}-\mathrm{H}$ bending vibrations of water, which is easily introduced into the system during the IR measurements [18].

The FT-IR spectrum of the needled sample, MW13(S950), indicated that it contained orthorhombic $\mathrm{MoO}_{3}$, which has two significant bands at $975 \mathrm{~cm}^{-1}$ for a terminal
$\mathrm{Mo}=\mathrm{O}$ stretching vibration and $840 \mathrm{~cm}^{-1}$ for the vibration of the Mo-O-Mo species [17]. Bands at 492 and $533 \mathrm{~cm}^{-1}$ were most likely due to asymmetric and symmetric stretches of the monoclinic $\mathrm{MoO}_{3}$ phase (Figure 12). As previously mentioned, the bands at 1625 and $3430 \mathrm{~cm}^{-1}$ were assigned to the $\mathrm{H}-\mathrm{O}-\mathrm{H}$ bending and stretching vibrations of the hydration water [19].

It is known that molybdenum oxide $\left(\mathrm{MoO}_{3}\right)$ melts and sublimes at approximately $800^{\circ} \mathrm{C}[20,21]$. However, according to the XRD patterns and the FT-IR spectra in the 


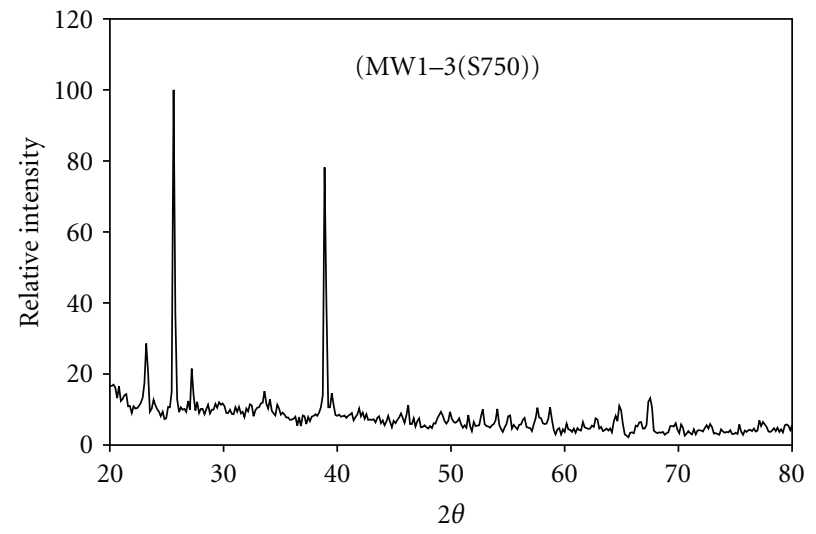

(a)

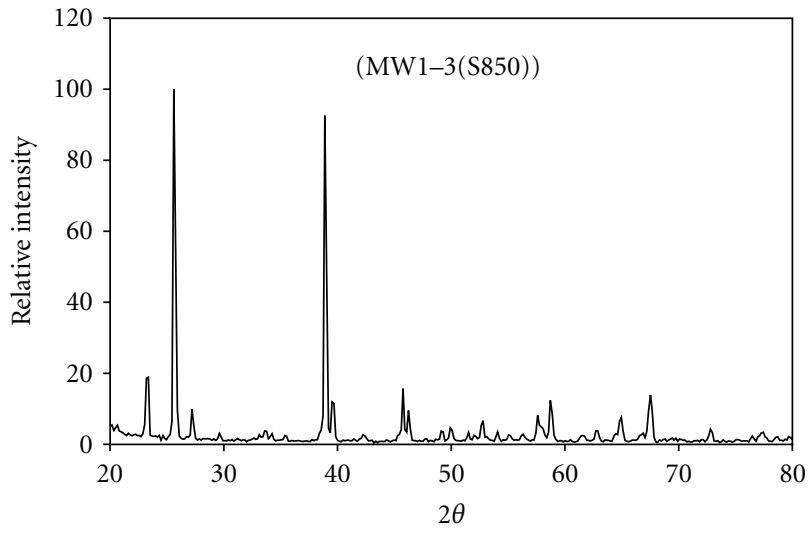

(b)

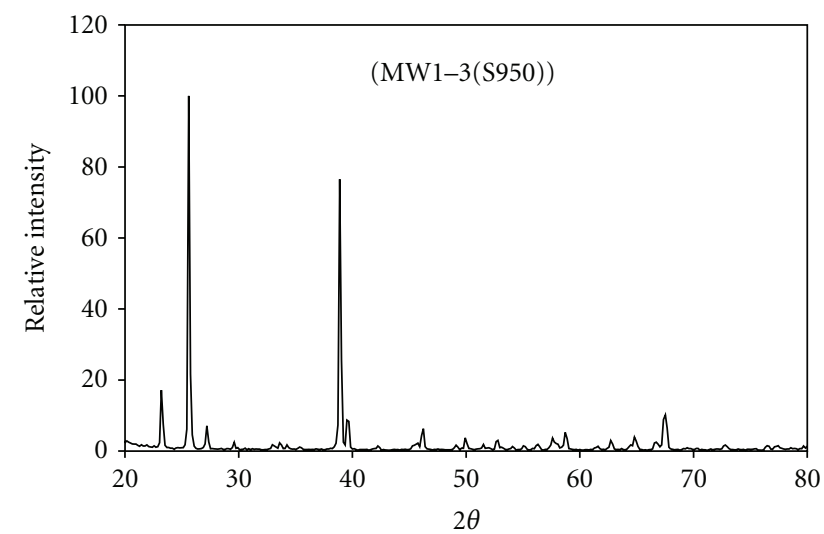

(c)

Figure 10: XRD patterns of (a) MW1-3(S750), (b) MW1-3(S850), and (c) MW1-3(S950).

presented case study, the decomposition of the bimetallic nanoparticles and, consequently, the sublimation process started early (i.e., at approximately $700^{\circ} \mathrm{C}$ ). Such an assumption was confirmed via the thermal analysis of MW13, where the thermal profile of the MoW nanoparticles (Figure 13) showed a strong decline in the DSC curve towards the endothermic direction at temperatures higher than $650^{\circ} \mathrm{C}$.

No significant endothermic peak was identified until $880^{\circ} \mathrm{C}$, and then another endothermic peak appeared at $933^{\circ} \mathrm{C}$. The thermal behavior of the MW1-3 sample may be explained as follows. Between 700 and $800^{\circ} \mathrm{C}$, the decomposition and deformation of the $\mathrm{Mo}_{0.5} \mathrm{~W}_{0.5} \mathrm{O}_{3}$ phase occurred, as did sublimation of the free $\mathrm{MoO}_{3}$ particles. The sublimation of the free $\mathrm{MoO}_{3}$ at such a relatively low temperature with respect to the normal thermal behavior of the molybdenum oxide bulk phase $[20,21]$ might be due to its size. On a nano-scale, the particles become more sensitive to thermal changes and, consequently, make the thermal transformation process easier than that for bulky particles.

At temperatures from 800 to $900^{\circ} \mathrm{C}$, the $\mathrm{W}_{0.47} \mathrm{Mo}_{0.53} \mathrm{O}_{3}$ and $\mathrm{W}_{0.4} \mathrm{Mo}_{0.6} \mathrm{O}_{3}$ phases deformed into $\mathrm{W}_{0.71} \mathrm{Mo}_{0.29} \mathrm{O}_{3}$. This deformation was accompanied by sublimation of the produced free $\mathrm{MoO}_{3}$ phase. At $933^{\circ} \mathrm{C}$, the final form of the
MoW nanoparticles, $\mathrm{W}_{0.71} \mathrm{Mo}_{0.29} \mathrm{O}_{3}$, lost its molybdenum component and transformed into triclinic $\mathrm{WO}_{3}$.

The TEM images of the MW1-3 and MW1-3(650) samples, which are similar in their phase compositions (Figures 14(a) and 4(b)), illustrated that the average particle sizes increased from $3-10 \mathrm{~nm}$ to $6-16 \mathrm{~nm}$ as the calcination temperature increased from 500 to $650^{\circ} \mathrm{C}$. Despite a change in the type of phases created after thermal treatment at high calcination temperatures (i.e., 750 and $850^{\circ} \mathrm{C}$ ), the general feature of these powdered samples was a low average particle size (6-11 nm for MW1-3(750) and 3-10 nm for MW13(850); Figures 14(c) and 14(d), resp.).

The TEM images of the nanoparticles of the triclinic tungsten oxide sample MW1-3(950) large agglomerates with average particle sizes from 46 to $115 \mathrm{~nm}$ (Figure 14(e)). By focusing on these agglomerates, the TEM image showed nanoparticles with average particle sizes from 1 to $12 \mathrm{~nm}$, which appeared as black spots, in addition to nonmeasurable ultra-fine nanoparticles with diameters smaller than $1 \mathrm{~nm}$ (dark gray patches distributed around the larger nanoparticles, Figure 14(f)).

3.2.2. Influence of Calcination Time. As mentioned above, the optimal temperature for the calcination process was 


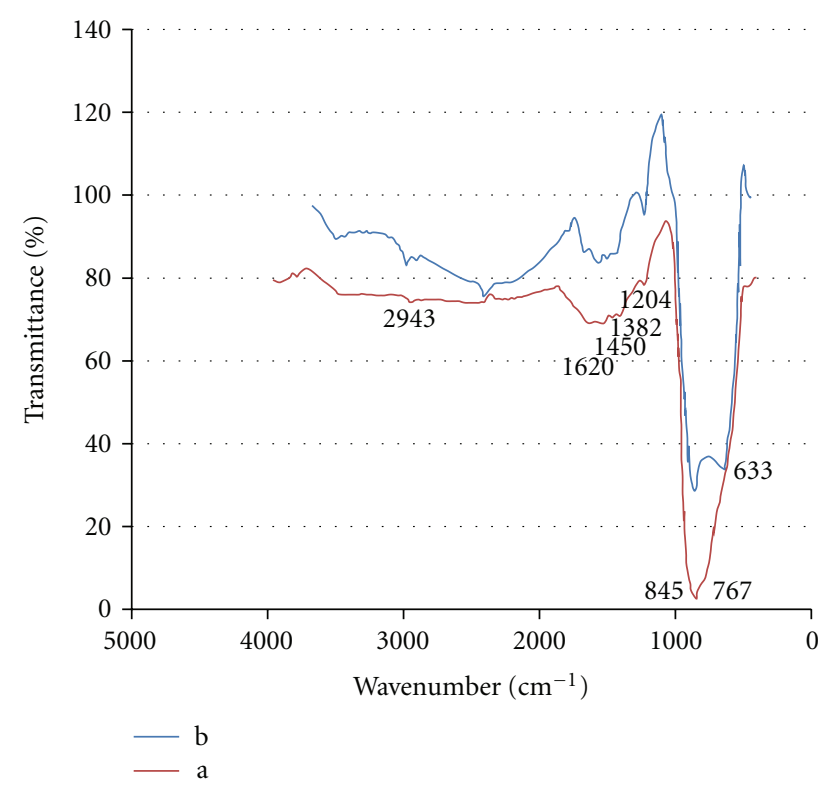

Figure 11: FTIR spectra of (a) MW1-3 and (b) MW1-3(950).

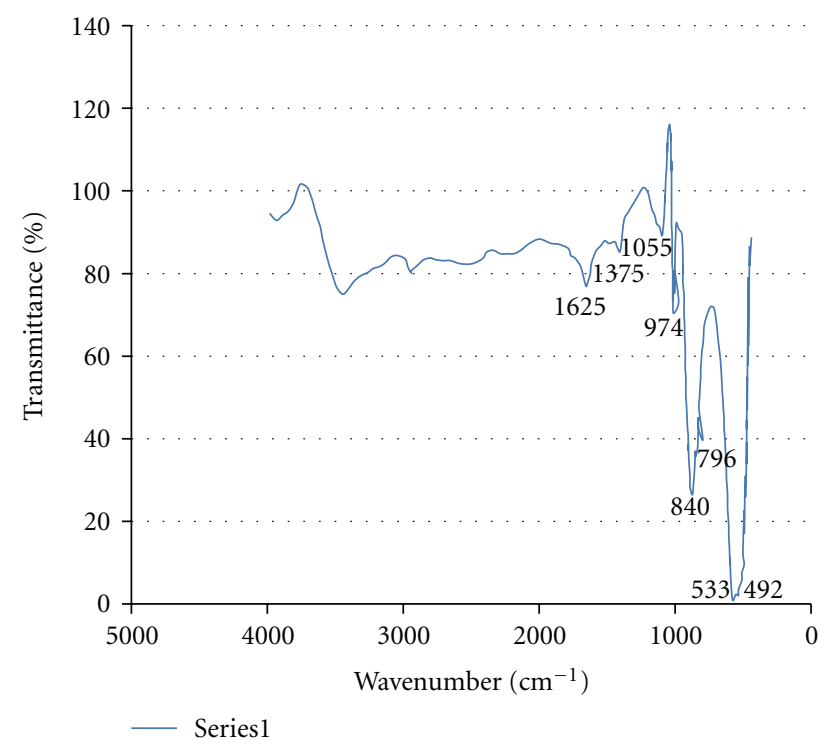

FIGURE 12: FTIR spectrum of MW1-3(S950).

$500^{\circ} \mathrm{C}$. However, there is another factor that may play an important role in the thermal treatment of bimetallic nanoparticles: the duration of the calcination process. To understand the importance of this factor, the influence of three different calcination times, four, eight, and twelve hours, on the characteristics of the final product were investigated. The bimetallic oxide samples that underwent the different calcination times are labeled MW1-3(8) and MW1-3(12), referring to calcination for eight and twelve hours, respectively. In addition, the MW1-3 sample was tested, which was calcined for four hours at $500^{\circ} \mathrm{C}$.

The X-ray diffraction patterns of the nanoparticles produced after different thermal treatment times (Figure 15)

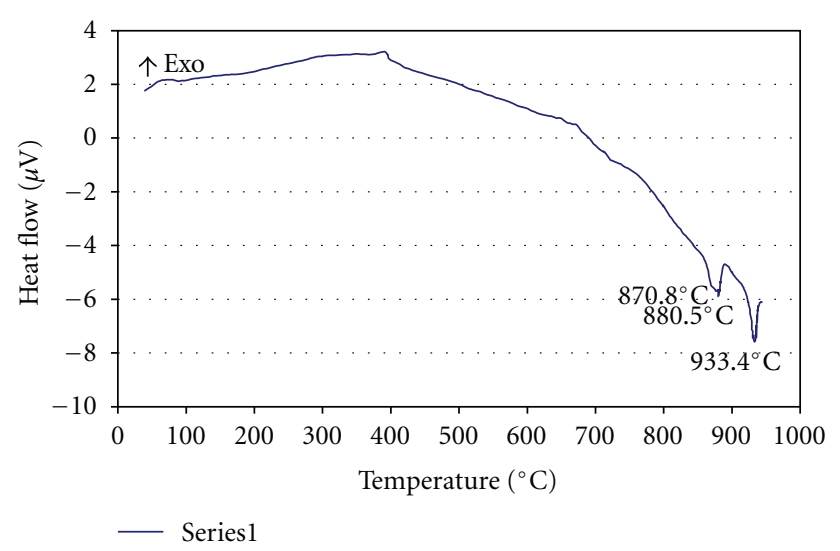

FIgURE 13: Thermal analysis (DSC) of MW1-3.

showed that increased calcination time did not significantly change the crystallinity of the produced nanobimetallic oxides. This assertion was supported by the unchanging intensities of the reflections in the oxides.

The reflection that belonged to the monometallic phases monoclinic $\mathrm{MoO}_{3}$ (JCPD: 80-0347) and cubic $\mathrm{WO}_{3}$ (JCPD: 41-0905), which could easily be identified in the XRD pattern of MW1-3 (Figure 15(a)), weakened and became indistinct after eight hours of calcination at $500^{\circ} \mathrm{C}$ (Figure $15(\mathrm{~b})$ ). Such reflections disappeared in the X-ray pattern of MW1-3(12), indicating that the produced nanoparticles of molybdenum-tungsten were a pure bimetallic $\mathrm{Mo}_{0.5} \mathrm{~W}_{0.5} \mathrm{O}_{3}$ phase (JCPD: 28-0667, Figure 15(c)).

The TEM image of the nanoparticles of MW1-3(8) did not show a distinct difference in average particle size (Figure 16(b)) when compared with the TEM image of the nanoparticles of MW1-3 (Figure 16(a)). Both samples had average particle sizes from 3 to $10 \mathrm{~nm}$. This observation eliminated the possibility of sintering during the long calcination time. On the contrary, increased calcination time was advantageous, as it gave the monoclinic $\mathrm{MoO}_{3}$ and cubic $\mathrm{WO}_{3}$ phases enough time to transform into the desired bimetallic $\mathrm{Mo}_{0.5} \mathrm{~W}_{0.5} \mathrm{O}_{3}$ phase.

Upon initial inspection, the TEM image of the nanoparticles of the bimetallic $\mathrm{Mo}_{0.5} \mathrm{~W}_{0.5} \mathrm{O}_{3}$ phase in MW1-3(12) indicated large agglomerates with average particle sizes from 41 to $160 \mathrm{~nm}$ (Figure 16(c)). By zooming on these agglomerates, however, the TEM image revealed nanoparticles with average particle sizes from 2 to $9 \mathrm{~nm}$, which appeared as black spots, in addition to nonmeasurable ultrafine nanoparticles with diameters smaller than $2 \mathrm{~nm}$ (dark gray patches Figure 16(d)).

\section{Conclusions}

The Pechini method can be successfully applied for the preparation of $\mathrm{Mo}_{0.5} \mathrm{~W}_{0.5} \mathrm{O}_{3}$, and the ratios of the reactants strongly affected the purity of the final products.

(i) The molar ratios $\mathrm{CA}: \mathrm{TM}=2$ and $\mathrm{EG}$ : $\mathrm{CA}=1.5$ were the most favorable for the preparation of $\mathrm{Mo}_{0.5} \mathrm{~W}_{0.5} \mathrm{O}_{3}$ nanoparticles having average particle 


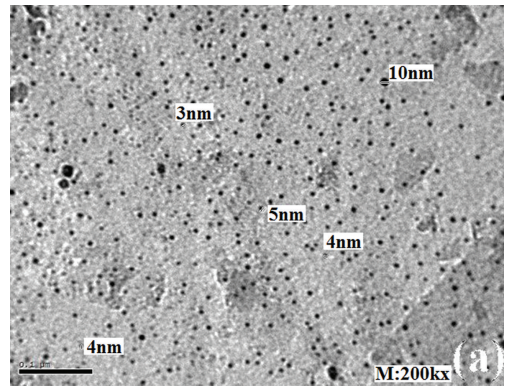

(a)

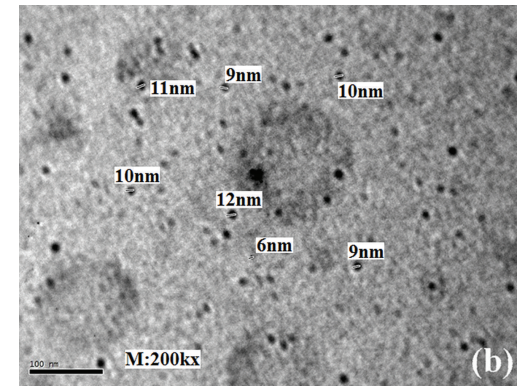

(b)

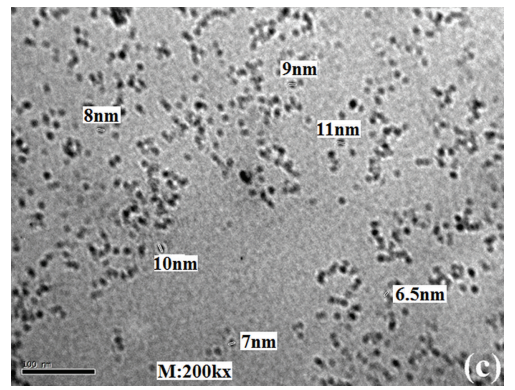

(c)

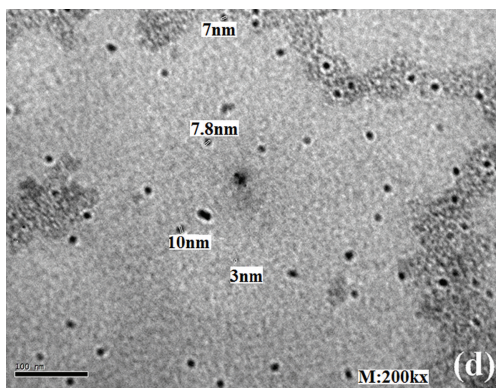

(d)

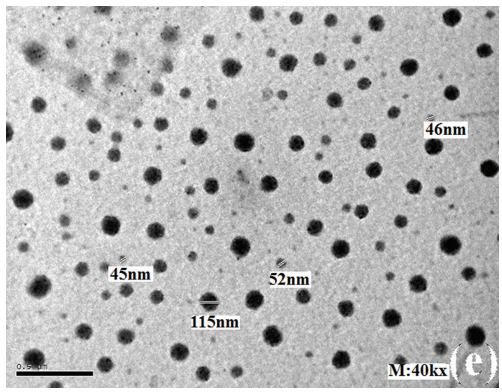

(e)

FIGURE 14: Transmission electron micrographs of nanocrystalline particles of (a) MW1-3, (b) MW1-3(650), (c) MW1-3(750), (d) MW13(850), (e) MW1-3(950), and (e) MW1-3(950).

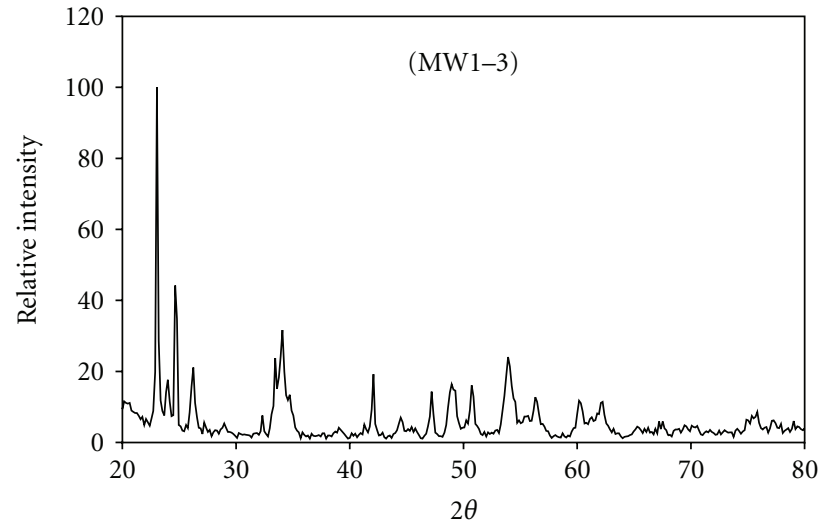

(a)

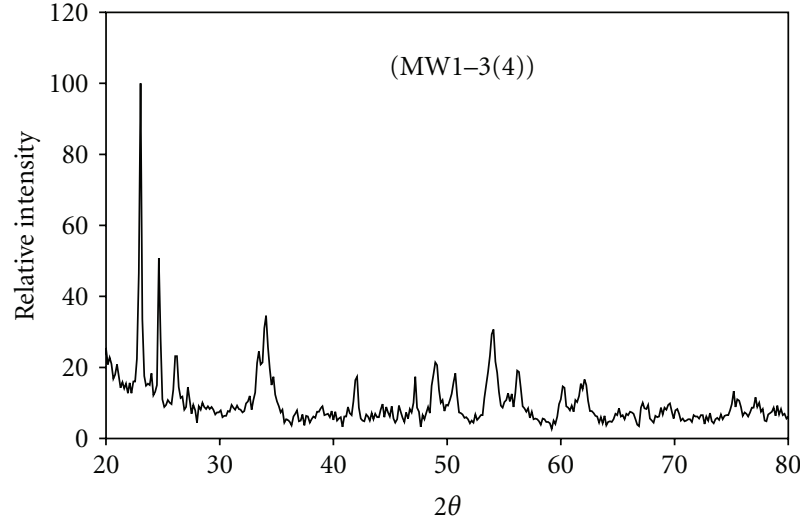

(b)

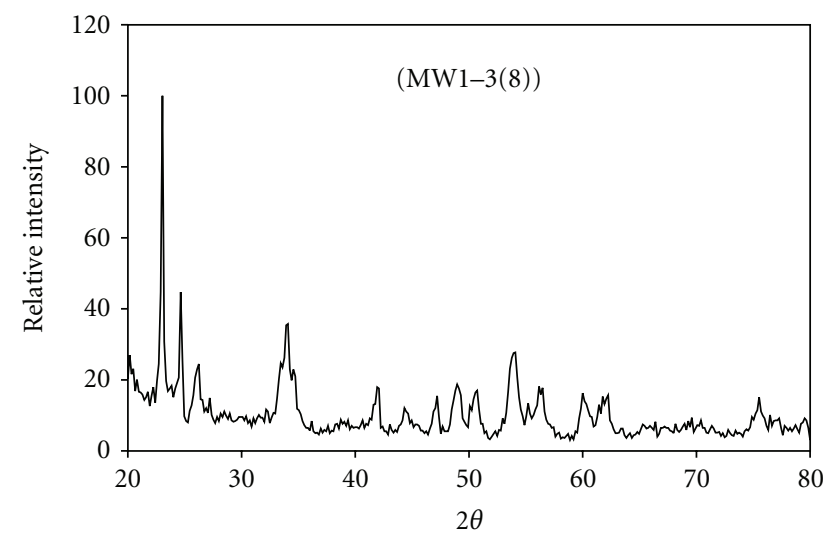

(c)

FIGURE 15: XRD patterns of (a) MW1-3, (b) MW1-3(4), and (c) MW1-3(8). 


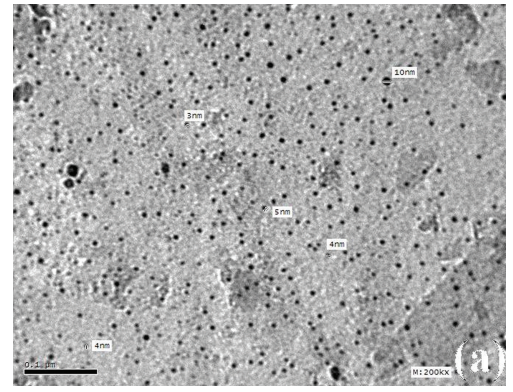

(a)

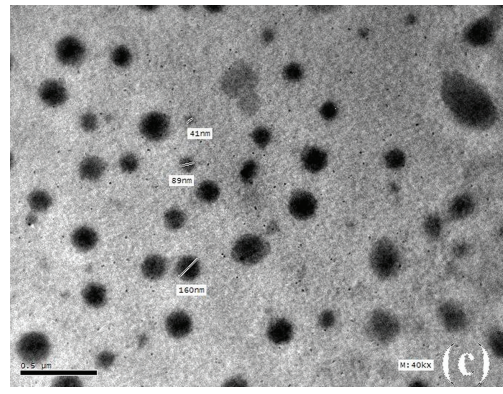

(c)

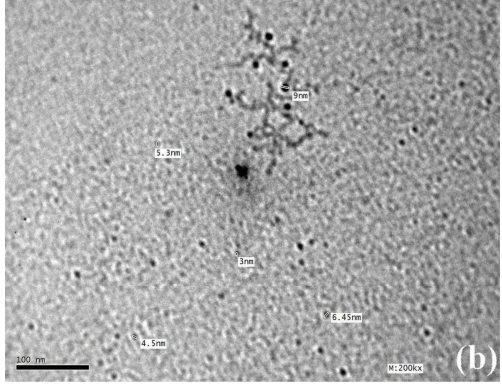

(b)

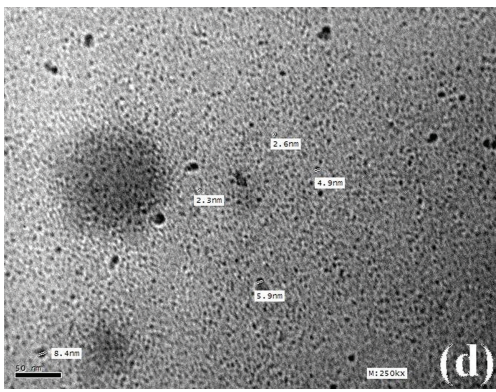

(d)

FIGURE 16: Transmission electron micrographs of nanocrystalline particles of (a) MW1-3, (b) MW1-3(8), (c) MW1-3(12), and (d) MW1$3(12)$.

sizes from 2 to $9 \mathrm{~nm}$. Meanwhile, the molar ratios $\mathrm{CA}: \mathrm{TM}=4$ and $\mathrm{EG}: \mathrm{CA}=0.19$ were optimal for the preparation of $\mathrm{Mo}_{0.5} \mathrm{~W}_{0.5} \mathrm{O}_{3}$ nanoparticles having average particle sizes from 11 to $29 \mathrm{~nm}$.

(ii) The sequence of the preparation steps affects nanoparticle dispersion, whereas the polyesterification reaction, as a starting step, also strongly influenced the dispersion of the nanoparticles.

(iii) Increased calcination time (eight hours) at a suitable temperature $\left(500^{\circ} \mathrm{C}\right)$ was advantageous, as it gave the monometallic phases enough time to transform into the desired bimetallic $\mathrm{W}_{0.5} \mathrm{Mo}_{0.5} \mathrm{O}_{3}$ phase.

\section{References}

[1] Y.-C. Nah, A. Ghicov, D. Kim, and P. Schmuki, "Enhanced electrochromic properties of self-organized nanoporous $\mathrm{WO}_{3}$," Electrochemistry Communications, vol. 10, no. 11, pp. 1777-1780, 2008.

[2] O. Marin-Flores, T. Turba, J. Breit, M. Norton, and S. $\mathrm{Ha}$, "Thermodynamic and experimental study of the partial oxidation of a Jet A fuel surrogate over molybdenum dioxide," Applied Catalysis A, vol. 381, no. 1-2, pp. 18-25, 2010.

[3] W. W. Qu and W. Wlodarski, "A thin-film sensing element for ozone, humidity and temperature," Sensors and Actuators B, vol. 64 , no. $1-3$, pp. 42-48, 2000.

[4] S. Morandi, G. Ghiotti, A. Chiorino, B. Bonelli, E. Comini, and G. Sberveglieri, " $\mathrm{MoO}_{3}-\mathrm{WO}_{3}$ mixed oxide powder and thin films for gas sensing devices: a spectroscopic characterisation," Sensors and Actuators B, vol. 111-112, pp. 28-35, 2005.

[5] D. Lokhat, M. Starzak, and M. Stelmachowski, "Gas-phase metathesis of 1-hexene over a $\mathrm{WO}_{3} / \mathrm{SiO}_{2}$ catalyst: search for optimal reaction conditions," Applied Catalysis A, vol. 351, no. 2, pp. 137-147, 2008.

[6] G. Lu, X. Li, Z. Qu, Y. Wang, and G. Chen, "Selective oxidation of cyclopentene to glutaraldehyde over the $\mathrm{WO}_{3} / \mathrm{SiO}_{2}$ catalyst," Applied Surface Science, vol. 255, no. 5, part 2, pp. 3117-3120, 2008.

[7] T. Ivanova, K. A. Gesheva, G. Popkirov, M. Ganchev, and E. Tzvetkova, "Electrochromic properties of atmospheric $\mathrm{CVD} \mathrm{MoO}_{3}$ and $\mathrm{MoO}_{3}-\mathrm{WO}_{3}$ films and their application in electrochromic devices," Materials Science and Engineering B, vol. 119, no. 3, pp. 232-239, 2005.

[8] C. Genin, A. Driouiche, B. Gérand, and M. Figlarz, "Hydrogen bronzes of new oxides of the $\mathrm{WO}_{3}-\mathrm{MoO}_{3}$ system with hexagonal, pyrochlore and $\mathrm{ReO}_{3}$-type structures," Solid State Ionics, vol. 53-56, no. 1, pp. 315-323, 1992.

[9] J. Purans, A. Kuzmin, P. Parent, and H. Dexpert, "In situ XAFS study of phase transitions and hydrogen intercalation in $\mathrm{WO}_{3}$ $\mathrm{MoO}_{3}$ system," Physica B, vol. 208-209, pp. 707-708, 1995.

[10] C.-Y. Su, C.-K. Lin, T.-K. Yang, H.-C. Lin, and C.-T. Pan, "Oxygen partial pressure effect on the preparation of nanocrystalline tungsten oxide powders by a plasma arc gas condensation technique," International Journal of Refractory Metals and Hard Materials, vol. 26, no. 5, pp. 423-428, 2008.

[11] A. F. Fuentes, O. Hernández-Ibarra, G. Mendoza-Suarez, J. I. Escalante-García, K. Boulahya, and U. Amador, "Structural analysis of several $\mathrm{W}(\mathrm{VI})$ and $\mathrm{Mo}(\mathrm{VI})$ complex perovskites prepared by the polymeric precursors method," Journal of Solid State Chemistry, vol. 173, no. 2, pp. 319-327, 2003.

[12] C. A. Kodaira, H. F. Brito, O. L. Malta, and O. A. Serra, "Luminescence and energy transfer of the europium (III) tungstate obtained via the Pechini method," Journal of Luminescence, vol. 101, no. 1-2, pp. 11-21, 2003.

[13] K. Galatsis, Y. X. Li, W. Wlodarski et al., "Comparison of single and binary oxide $\mathrm{MoO}_{3}, \mathrm{TiO}_{2}$ and $\mathrm{WO}_{3}$ sol-gel gas sensors," Sensors and Actuators B, vol. 83, no. 1-3, pp. 276-280, 2002. 
[14] C. Malagù, M. C. Carotta, S. Morandi et al., "Surface barrier modulation and diffuse reflectance spectroscopy of $\mathrm{MoO}_{3}$ $\mathrm{WO}_{3}$ thick films," Sensors and Actuators B, vol. 118, no. 1-2, pp. 94-97, 2006.

[15] W. Zhu, H. Li, X. He, Q. Zhang, H. Shu, and Y. Yan, "Synthesis of adipic acid catalyzed by surfactant-type peroxotungstates and peroxomolybdates," Catalysis Communications, vol. 9, no. 4, pp. 551-555, 2008.

[16] A. Sarkar, S. Pramanik, A. Achariya, and P. Pramanik, "A novel sol-gel synthesis of mesoporous $\mathrm{ZrO}_{2}-\mathrm{MoO}_{3} / \mathrm{WO}_{3}$ mixed oxides," Microporous and Mesoporous Materials, vol. 115, no. 3, pp. 426-431, 2008.

[17] V. P. Tolstoy, I. V. Chernyshova, and V. A. Skryshevsky, Handbook of Infrared Spectroscopy of Ultrathin Films, John Wiley \& Sons, Hoboken, NJ, USA, 2003.

[18] J. Yu, L. Qi, B. Cheng, and X. Zhao, "Effect of calcination temperatures on microstructures and photocatalytic activity of tungsten trioxide hollow microspheres," Journal of Hazardous Materials, vol. 160, no. 2-3, pp. 621-628, 2008.

[19] S. Wang, C. An, Y. Zhang, Z. Zhang, and Y. Qian, "Ethanothermal reduction to $\mathrm{MoO}_{2}$ microspheres via modified Pechini method," Journal of Crystal Growth, vol. 293, no. 1, pp. 209215, 2006.

[20] H. G. El-Shobaky, M. Mokhtar, and A. S. Ahmed, "Effect of $\mathrm{MgO}$-doping on solid-solid interactions in $\mathrm{MoO}_{3} / \mathrm{Al}_{2} \mathrm{O}_{3}$ system," Thermochimica Acta, vol. 327, no. 1-2, pp. 39-46, 1999.

[21] W. M. Shaheen, "Thermal solid-solid interaction and catalytic properties of $\mathrm{CuO} / \mathrm{Al}_{2} \mathrm{O}_{3}$ system treated with $\mathrm{ZnO}$ and $\mathrm{MoO}_{3}$," Thermochimica Acta, vol. 385, no. 1-2, pp. 105-116, 2002. 

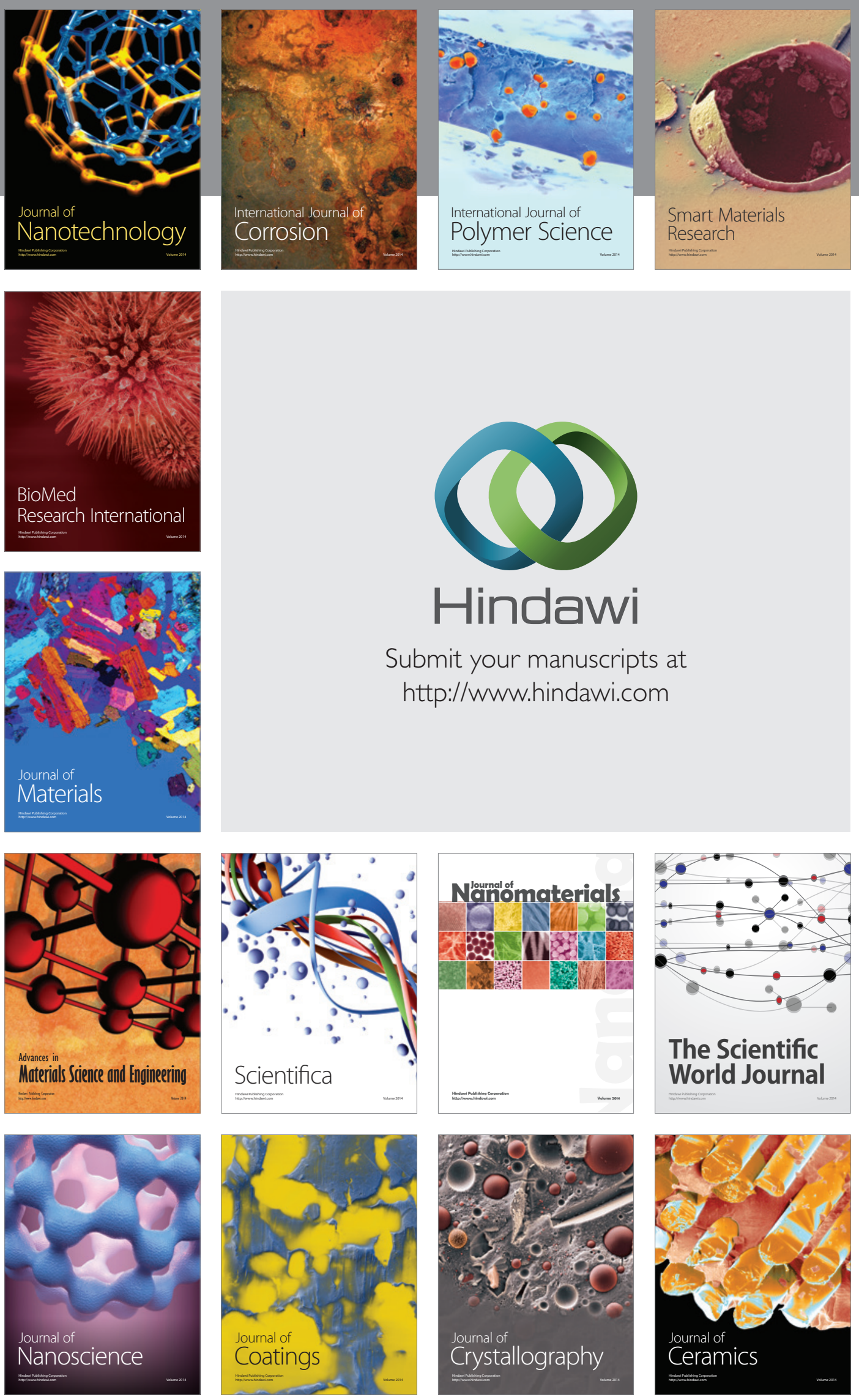

The Scientific World Journal

Submit your manuscripts at

http://www.hindawi.com

\section{World Journal}

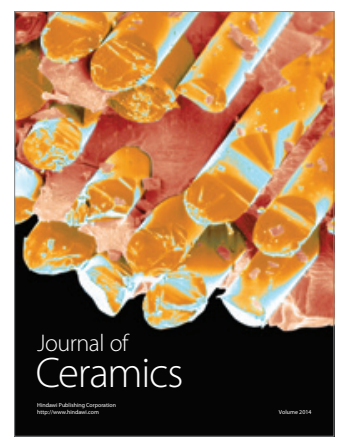

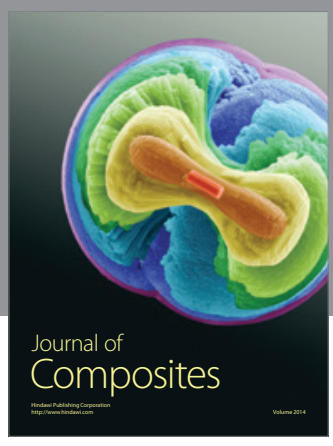
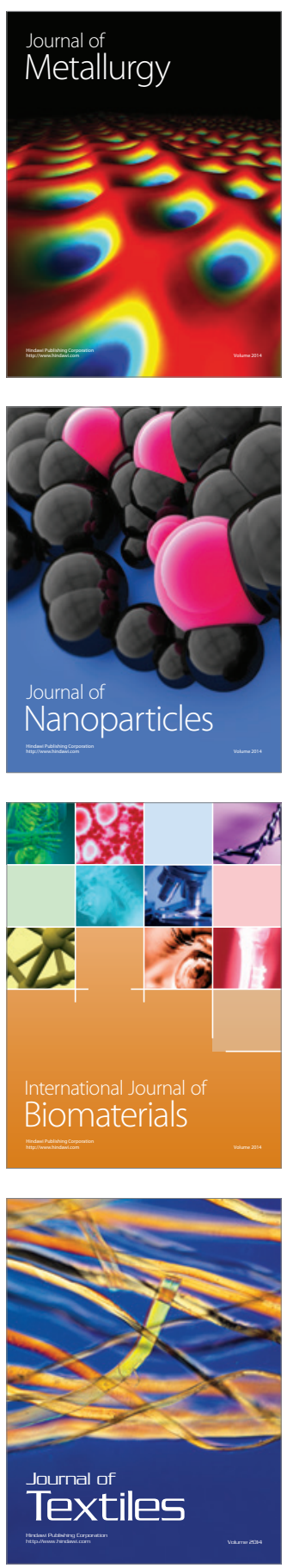